Full length article

\title{
Effect of ischemic preconditioning and a Kv7 channel blocker on cardiac ischemia-reperfusion injury in rats
}

\author{
Krestine Kjeldsen Corydon ${ }^{\mathrm{a}}$, Vladimir Matchkov ${ }^{\mathrm{a}}$, Rafael Fais ${ }^{\mathrm{a}, \mathrm{b}}$, Denis Abramochkin ${ }^{\mathrm{c}, \mathrm{d}, \mathrm{e}}$, \\ Elise Røge Hedegaard ${ }^{\mathrm{a}}$, Simon Comerma-Steffensen ${ }^{\mathrm{a}, \mathrm{f}}$, Ulf Simonsen ${ }^{\mathrm{a}, *}$ \\ a Department of Biomedicine, Pulmonary and Cardiovascular Pharmacology and Physiology, Aarhus University, Wilhelm Meyers Allé 4, 8000, Aarhus C, Denmark \\ ${ }^{\mathrm{b}}$ Department of Pharmacology, Ribeirao Preto Medical School, University of Sao Paulo, Ribeirao Preto, São Paulo, Brazil \\ ${ }^{\mathrm{c}}$ Department of Human and Animal Physiology, Biological Faculty, Lomonosov Moscow State University, Leninskiye Gory, 1, 12, Moscow, Russia \\ ${ }^{\mathrm{d}}$ Ural Federal University, Mira 19, Ekaterinburg, Russia

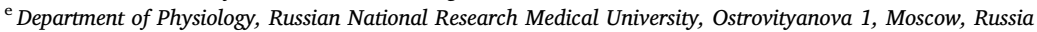 \\ ${ }^{\mathrm{f}}$ Department of Biomedical Sciences/Animal Physiology, Veterinary Faculty, Central University of Venezuela, Maracay, Aragua, Venezuela
}

\section{A R T I C L E I N F O}

\section{Keywords:}

Acute myocardial infarction

XE991

Cardioprotection

Blood pressure

Rat

In vivo

\begin{abstract}
A B S T R A C T
Recently, we found cardioprotective effects of ischemic preconditioning (IPC), and from a blocker of KCNQ voltage-gated $\mathrm{K}^{+}$channels ( $\left.\mathrm{K}_{\mathrm{V}} 7\right)$, XE991 (10,10-bis(4-pyridinylmethyl)-9(10H)-anthracenone), in isolated rat hearts. The purpose of the present study was to investigate the cardiovascular effects of IPC and XE991 and whether they are cardioprotective in intact rats. In conscious rats, we measured the effect of the $\mathrm{K}_{\mathrm{V}} 7$ channel blocker XE991 on heart rate and blood pressure by use of telemetry. In anesthetized rats, cardiac ischemia was induced by occluding the left coronary artery, and the animals received IPC ( $2 \times 5$ min of occlusion), XE991, or a combination. After a $2 \mathrm{~h}$ reperfusion period, the hearts were excised, and the area at risk and infarct size were determined. In both anesthetized and conscious rats, XE991 increased blood pressure, and the highest dose $(7.5 \mathrm{mg} / \mathrm{kg})$ of XE991 also increased heart rate, and 44\% of conscious rats died. XE991 induced marked changes in the electrocardiogram (e.g., increased $\mathrm{PR}$ interval and prolonged $\mathrm{QT}_{\mathrm{C}}$ interval) without changing cardiac action potentials. The infarct size to area at risk ratio was reduced from $53 \pm 2 \%(\mathrm{n}=8)$ in the vehicle compared to $36 \pm 3 \%$ in the IPC group $(\mathrm{P}<0.05, \mathrm{n}=9)$. XE991 $(0.75 \mathrm{mg} / \mathrm{kg})$ treatment alone or on top of IPC failed to reduce myocardial infarct size. Similar to the effect in isolated hearts, locally applied IPC was cardioprotective in intact animals exposed to ischemia-reperfusion. Systemic administration of XE991 failed to protect the heart against ischemia-reperfusion injury suggesting effects on the autonomic nervous system counteracting the cardioprotection in intact animals.
\end{abstract}

\section{Introduction}

Treatment of acute myocardial infarction (AMI) aims to remove the occlusion in the affected coronary artery and thereby re-establish blood flow. Although reperfusion is essential, it can itself damage the myocardium - a phenomenon known as reperfusion injury (Yellon and Hausenloy, 2007). Ischemic preconditioning (IPC), which consists of a series of short ischemic episodes to a target tissue, protects the heart against ischemic-reperfusion injury (Murry et al., 1986; Piot et al., 1997; Li et al., 1992). In animal studies, the ability of conditioning to protect the heart is convincing, however in the clinical setting, results are not as conclusive (Davies et al., 2013; Hausenloy et al., 2015; Walsh et al., 2016; Botker et al., 2010).

Activation of large-conductance $\mathrm{Ca}^{2+}$ activated $\mathrm{K}^{+}$channels protects against ischemia-reperfusion injury, and inhibition of mitochondrial ATP-sensitive $\mathrm{K}$ channels $\left(\mathrm{K}_{\mathrm{ATP}}\right)$ channels partially abolishes ischemic preconditioning (IPC) induced cardioprotection (Fryer et al., 2000; Bentzen et al., 2009). The role of voltage-gated $\mathrm{K}^{+}$channels type $7\left(\mathrm{~K}_{\mathrm{V}} 7\right)$ in the heart is not well established (Hedegaard et al., 2016; Testai et al., 2016). The $K_{V} 7$ subtypes $\left(K_{V} 7.1-7.5\right)$ are expressed in rat and porcine left and right ventricles, coronary arteries and brain tissue, as well as in the human heart (Hedegaard et al., 2014, 2016; Khanamiri et al., 2013; Tinel et al., 1998; Ng et al., 2011). The $\mathrm{K}_{\mathrm{V}} 7$ channels contribute to the resting membrane potential in vascular smooth muscle cells (Mackie and Byron, 2008). Blockade of $\mathrm{K}_{\mathrm{v}} 7$ channels increases vascular tone in rodent blood vessels (Yeung et al., 2007; Yeung and Greenwood, 2005; Mackie et al., 2008), and prevents apoptosis in rat sympathetic neurons, suggesting a cytoprotective effect

\footnotetext{
* Corresponding author. Department of Biomedicine, Aarhus University, Wilhelm Meyers Allé 4, DK-8000, Aarhus C, Denmark.

E-mail address: us@biomed.au.dk (U. Simonsen).
} 
(Xia et al., 2002). A putative opener of $K_{V} 7$ channels, retigabine, was reported to protect isolated rat hearts against ischemia-reperfusion injury, and this was antagonized by a blockade of $\mathrm{K}_{\mathrm{V}} 7$ channels (Testai et al., 2016). However, a high concentration of retigabine was used, which may also block myocardial voltage-gated $\mathrm{K}^{+}$channels (Rundfeldt, 1997). We found that the pan- $\mathrm{K}_{\mathrm{V}} 7$ channel blockers XE991 and linopirdine (Wang et al., 1998, 2000; Jensen et al., 2005), reduce infarct size in isolated rat hearts and post-hypoxia-reoxygenation cell death in the HL cardiomyocyte cell line approximately 30\% (Hedegaard et al., 2016). Moreover, an additive protective effect was observed by combining $\mathrm{K}_{\mathrm{V}} 7$ inhibition and IPC treatment. Furthermore, an opener of $\mathrm{K}_{\mathrm{V}} 7$-channels abrogates the cardio-protective effects of IPC (Hedegaard et al., 2016). However, it is unclear whether systemic administration of $\mathrm{K}_{\mathrm{V}} 7$ channel blockers exerts cardioprotective effects in intact animals.

We hypothesized that administration of a $\mathrm{K}_{\mathrm{V}} 7$ channel blocker would reduce ischemia-reperfusion injury in intact animals. To choose the dose, we examined the effect of XE991 administration on heart rate, blood pressure, and electrocardiogram (ECG) in intact animals. To investigate the effect of IPC and the $\mathrm{K}_{\mathrm{V}} 7$ channel blocker XE991 in an in vivo rat model of AMI, we experimentally induced myocardial infarction in rats by ligating the left anterior descending coronary artery (LAD), followed by evaluation of myocardial infarct size.

\section{Material and methods}

\subsection{Animals}

The animals were handled in accordance with national and institutional guidelines for animal research and the experimental work approved by the Danish Animal Experiments Expectorate (license no. 2016-15-0201-00948 and 2016-15-0201-00982). Male Wistar rats (Janvier, France) were used at 7-8 weeks of age in the AMI study, and 11-12 weeks of age in both the telemetry and myograph study. The rats were housed in the animal facility in cages (Universal Euro III type long) with standard wood bedding, received standard diet and had access to water ad libitum, and were kept under temperature and humidity-controlled conditions with $12 \mathrm{~h} / 12 \mathrm{~h}$ light/dark cycles, respectively.

\subsection{Materials}

Isoprenaline $\mathrm{HCl}$, phenylephrine $\mathrm{HCl}, \mathrm{U} 4661$ (9[(5Z)-7[(1R,4S,5S,6R)-6-[(1E,3S)-3- hydroxy-1-octenyl]-2-oxabicyclo[2.2.1] hept-5-yl]-5-heptenoic acid]), prazosin $\mathrm{HCl}$, yohimbine, XE991 [10,10bis(4-pyridinylmethyl)-9(10H)-anthracenone], Evans blue 1\%, 2,3,5Triphenyltetrazolium chloride (TTC) $1 \%$, formaldehyde $4 \%$ buffered, dimethylsulphoxide (DMSO) $\geq 99 \%$, Dulbecco's Phosphate buffered saline, (D8537) (All from Sigma-Aldrich, St. Louis USA).

\subsection{Telemetric measurements of mean arterial blood pressure (MAP) and heart rate}

To examine hemodynamic changes after administration of XE991 in conscious rats, we measured blood pressure and heart rate continuously using radiotelemetry as previously described (Laursen et al., 2017). The rats were anesthetized by a combination of ketamine $(3 \mathrm{mg} / \mathrm{kg}$; Ketaminol ${ }^{\oplus}$ vet, Intervet International, AN Boxmeer, Netherlands) and xylazine $\left(0.75 \mathrm{mg} / \mathrm{kg}\right.$; $\mathrm{Narcoxyl}^{\oplus} \mathrm{vet}$, Intervet International, AN Boxmeer, Netherlands), and a telemetric transducer (TA11PA-C40; Data Sciences International, ST. Paul, MN, USA) was implanted. The abdominal skin of the anesthetized rat was shaved and sterilized, and a midline incision was made through the skin and abdominal wall. Surrounding intestines were retracted with saline moistened gauze to access the abdominal aorta. The aorta was separated from the caval vein, and a piece of 4-0 suture was placed underneath to occlude blood flow temporarily. Using a bend 22-gauge syringe needle, the catheter of the telemetric transducer was advanced into the aorta. A small amount of tissue adhesive (3M Vetbond, 3M Animal Care Product, St. Paul, MN, USA) was applied to anchor the catheter in place with a small fiber patch. The aorta occlusion and the gauze sponge retraction were removed. The transmitter was placed on top of the intestine. The abdominal wall and skin were closed by 4-0 suture, and analgesia (subcutaneously $0.2 \mathrm{mg}$ / kg; Temgesic, Reckitt Benckiser Healthcare Limited, Hull, UK) was injected.

The rats were allowed to recover for at least one week before the experimental protocol was started. Telemetry signals were recorded continuously for $2 \mathrm{~h}$, before a consequent administration of three doses of XE991 $(0.075 \mathrm{mg} / \mathrm{kg}, 0.75 \mathrm{mg} / \mathrm{kg}$ and $7.5 \mathrm{mg} / \mathrm{kg}$, intraperitoneally) with an interval of $2 \mathrm{~h}$ between each administration, allowing clearance of more than $90 \%$ of XE991 between each dosage assuming a half-life of $0.6 \mathrm{~h}$ as for the structurally similar compound linopirdine (Rakestraw et al., 1994). After each intraperitoneal injection, the rats were allowed to rest 10 min before we started the measuring to avoid stress affecting the results. Moreover, we have compared active drug to the vehicleinjected animals to examine the effect with XE991 as the only variable. Registration and analyses were performed with Dataquest A.R.T software 4.3 (Data Sciences International, St. Paul, MN, USA).

\subsection{Myograph experiments}

Rats were killed by a blow to the head, followed by exsanguination. The mesenteric bed was removed, and it was immediately placed in cold physiological salt solution $\left(4{ }^{\circ} \mathrm{C}\right)$ of the following composition (mM): $\mathrm{NaCl} 119, \mathrm{KCl} 4.7, \mathrm{KH}_{2} \mathrm{PO}_{4} 1.18, \mathrm{MgSO}_{4} 1.17, \mathrm{NaHCO}_{3} 25, \mathrm{CaCl}_{2}$ 1.6, EDTA 0.026 and glucose 5.5. To elucidate the effect of XE991 on vascular tone in resistance arteries, rat mesenteric small artery segments were isolated and mounted in microvascular myographs (Danish Myotechnology, Aarhus, Denmark) for isometric tension recordings as previously described (Bangshaab et al., 2019). The vessels were equilibrated in oxygenated $\left(5 \% \mathrm{CO}_{2}\right.$ in air) physiological salt solution $(\mathrm{pH}$ 7.4) heated to $37^{\circ} \mathrm{C}$. To determine the lumen diameter that the artery would have had in vivo when relaxed and under a transmural pressure of $100 \mathrm{mmHg}$, the vessels were stretch following a standardized procedure. Arteries were set to $90 \%$ of this diameter, which is the optimal vessel circumference for maximal force development (Mulvany and Halpern, 1977). To test tissue viability, arterial segments were subjected to an isotonic physiological salt solution containing a high concentration of potassium $(123 \mathrm{mM})$ or noradrenaline $\left(10^{-5} \mathrm{M}\right)$, resulting in maximal contraction of the vessels. To test endothelial function, the vessels were contracted with phenylephrine or noradrenaline and then stimulated with acetylcholine $(10 \mu \mathrm{M})$. To examine whether XE991 induced contraction, cumulative concentration-response curves for XE991 were performed at resting tension or in vessels contracted to $20 \%$ of the maximum response by addition of $10^{-6} \mathrm{M}$ phenylephrine. To examine whether XE991 inhibited relaxation, concentration-response curves for the $\beta$-adrenoceptor agonist, isoprenaline were obtained in arteries contracted with the thromboxane analog, U46619 $\left(10^{-7} \mathrm{M}\right)$, in the absence and presence of XE991 $\left(10^{-5} \mathrm{M}\right)$. To avoid contribution from $\alpha$-adrenoceptors to the isoprenaline responses, the curves were performed in the presence of prazosin $\left(10^{-6} \mathrm{M}\right)$ and yohimbine $\left(10^{-6} \mathrm{M}\right)$.

\subsection{Electrocardiographic (ECG) measurements}

$\mathrm{K}_{\mathrm{V}} 7$ channels are expressed in the conduction system and heart muscle fibers (Testai et al., 2016; Hedegaard et al., 2016; Sanguinetti et al., 1996). Therefore, in anesthetized animals, we examined the effect of XE991 compared to a vehicle on the electrical activity of the heart. Rats were anesthetized with S-ketamine hydrochloride $(60 \mathrm{mg} /$ $\mathrm{kg}$; Pfizer, Ballerup Denmark) and xylazine $(10 \mathrm{mg} / \mathrm{kg}$; Rompun vet, KVP Pharma + Veterinär produkte Bayer, Kiel Germany) mixture intraperitoneally. ECG was recorded for at least $30 \mathrm{~min}$ to ensure normal 
rhythm; following this, increasing doses of vehicle or XE991 were administered with $30 \mathrm{~min}$ intervals in two subgroups of animals. Data were obtained by the use of an animal bio-amplifier (AD Instruments Oxford, United Kingdom), and the software automatically obtained the different ECG values, as previously described (Comerma-Steffensen et al., 2017)., The ECG signals were low-pass filtered by using a standard filter for rats. The rate-corrected QT interval (QTc) was calculated using the standard Bazett's formula $\left(\mathrm{QT}_{\mathrm{C}}=\mathrm{QT} / \mathrm{VRR}\right)$.

\subsection{Action potential recordings in ventricular preparations}

To clarify whether there was a direct effect of XE991 on rat ventricular myocytes, we recorded action potentials as previously described (Abramochkin et al., 2018). Rats were anesthetized with intraperitoneal injection of $80 \mathrm{mg} / \mathrm{kg}$ ketamine and $10 \mathrm{mg} / \mathrm{kg}$ xylazine. Heparin $(1000 \mathrm{U} / \mathrm{kg})$ was added to the anesthetic solutions to prevent blood coagulation in the coronary vessels of the excised heart. The chest was opened and the heart was rapidly excised and rinsed with Tyrode solution of the following composition (in $\mathrm{mM}$ ): $\mathrm{NaCl} 118.0, \mathrm{KCl} \mathrm{2.7,}$ $\mathrm{NaH}_{2} \mathrm{PO} 42.2, \mathrm{MgCl}_{2} 1.2, \mathrm{CaCl}_{2} 1.2, \mathrm{NaHCO}_{3} 25.0$, glucose 11.0, bubbled with carbogen gas $(95 \% \mathrm{O} 2+5 \% \mathrm{CO} 2), \mathrm{pH} 7.4$. The preparations of right atrium (including the intercaval region) were isolated and pinned with the endocardial side up to the bottom of an experimental chamber $(3 \mathrm{ml})$ perfused with Tyrode solution $\left(10 \mathrm{ml} / \mathrm{min}, 37.5{ }^{\circ} \mathrm{C}\right)$. Since the right atrial preparations contained the sinoatrial node, they were beating spontaneously throughout the experiment.

After $1 \mathrm{~h}$ of equilibration in the perfusion chamber, transmembrane potentials were recorded from the endocardial surface of preparations with sharp glass microelectrodes (30-45 M $\Omega$ ) filled with $3 \mathrm{M} \mathrm{KCl}$ connected to a high input impedance amplifier Model 1600 (A-M Systems, Sequim, WA, USA). The signal was digitized and analyzed using specific software (L-card, Russia; DI-Soft, Russia; Synaptosoft, USA). Stable impalements were maintained during the entire period of XE991 $\left(10^{-5} \mathrm{M}\right)$ application. Changes in spontaneous beating rate and action potential duration at 50 and $90 \%$ of repolarization (APD90) were determined.

\subsection{The rat myocardial infarct model}

The rats were anesthetized with S-ketamine hydrochloride $(60 \mathrm{mg} /$ $\mathrm{kg}$; Pfizer, Ballerup Denmark) and xylazine (10 mg/kg; Rompun vet, KVP Pharma + Veterinär produkte Bayer, Kiel Germany) mixture intraperitoneally. One-third of these doses were applied approximately every $45 \mathrm{~min}$ to attain a constant level of anesthesia. After shaving, the rats were intubated and mechanically ventilated ( 80 breaths per min, tidal volume at $2 \mathrm{ml}$ per $100 \mathrm{~g}$ body weight, and $6 \mathrm{cmH}_{2} \mathrm{O}$ positive endexpiratory pressure). The rats were placed on a temperature-controlled heating pad to maintain body temperature, and a pulse oximeter (LifeVet, Eickemeyer, Vojens, Denmark) was connected to the animals. MAP and heart rate were measured continuously through a heparinfilled catheter placed in the left carotid artery through a midline incision on the neck and connected to a pressure transducer (ADInstruments MLT0699, Oxford, United Kingdom). The signal was recorded using Powerlab and LabChart (ADInstruments ML866 and ML118, Oxford, United Kingdom).

The rats were randomly assigned to four groups subjected to different protocols: vehicle, IPC, XE991, and one receiving both IPC and XE991. To access the heart, a thoracotomy in the third intercostal space was performed, and the 4th and 5th ribs were cut through. The thymus gland was moved aside, and the pericardium opened. Using a microscope (Nikon SMZ645, Amsterdam, Netherlands), the LAD was ligated using 6.0 silk suture with a taper point needle. The suture was threaded through a pearl and a small plastic tube to create a reversible snare, and the LAD was occluded according to the assigned group as illustrated in Fig. 1. Successful ligation was confirmed by blanching of myocardial tissue. Ischemia was induced by tightening the snare for $40 \mathrm{~min}$. After

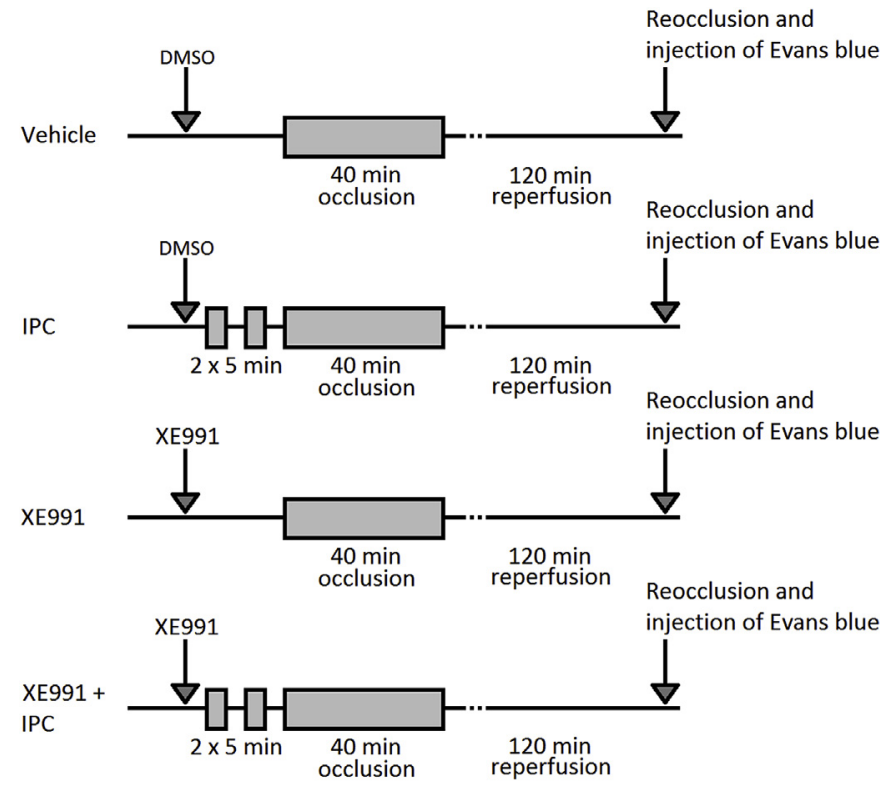

Fig. 1. Protocol design. Schematic illustration of the study design and experimental protocol. Grey areas represent periods with occlusion of the left anterior descending artery (LAD). DMSO, dimethylsulfoxide; IPC, ischemic preconditioning; XE991, $\mathrm{K}_{\mathrm{V}} 7$ channel blocker.

the ischemic insult, the snare was loosened, and the artery was reperfused for $2 \mathrm{~h}$. IPC was achieved via two $5 \mathrm{~min}$ cycles of LAD occlusion, each followed by $5 \mathrm{~min}$ of reperfusion. XE991 $(0.75 \mathrm{mg} / \mathrm{kg})$ dissolved in DMSO $(0.2 \mathrm{ml} / \mathrm{kg}$ of $3.765 \mathrm{mg}$ XE991/ml DMSO), was injected intraperitoneally $25 \mathrm{~min}$ before the main ischemic insult. The dosage of XE991 administered in our study was based on the concentrations previously used in isolated rat hearts (Hedegaard et al., 2016), and on an assumption of a volume of distribution of $2.0 \mathrm{~L} / \mathrm{kg}$ as for the structurally similar compound linopirdine (Rakestraw et al., 1994). This resulted in an estimated dose of $0.75 \mathrm{mg} / \mathrm{kg}$ XE991 that is equivalent to $1 \mu \mathrm{M}$ plasma concentration. The reason for selecting $0.75 \mathrm{mg} / \mathrm{kg}$ XE991 was also based on our telemetric studies depicting the effect of different doses of XE991 on MAP, and showing that the high dose of XE991 resulted in death in $44 \%$ of the animals (see results section 3.1). Animals that did not receive XE991 got an intraperitoneal injection with a corresponding amount of DMSO.

\subsection{Assessment of infarct size}

At the end of the $2 \mathrm{~h}$ reperfusion period, the LAD was re-occluded, and $1 \mathrm{ml}$ of $1 \%$ Evans blue in phosphate-buffered saline was injected into the left ventricle of the beating heart, circulating the accessible vasculature, thereby leaving the area at risk (AAR) unstained (modified from (Fiedler et al., 1982; Ovize et al., 1994). After 2 min with perfusion of Evans blue, the heart was excised and frozen at $-80{ }^{\circ} \mathrm{C}$ overnight. Next day, the heart was sliced transversely into five sections, which were gently rinsed with phosphate-buffered saline. To distinguish vital tissue from infarcted areas, the slices were submerged in a $1 \%$ TTC solution in phosphate-buffered saline at $37{ }^{\circ} \mathrm{C}$ for $3 \mathrm{~min}$, immersed in cold water, and stored in $4 \%$ formaldehyde overnight. Infarct size and AAR were assessed using ImageJ image analysis software (National Institutes of Health, Bethesda, MD, USA). Total area of the slices, AAR, and infarct size were measured, and each measurement was weighted with the weight of each individual slice. The evaluation of infarct size was performed using images with assigned numbers not related to the received treatment, and hence blinding the observer. 
A

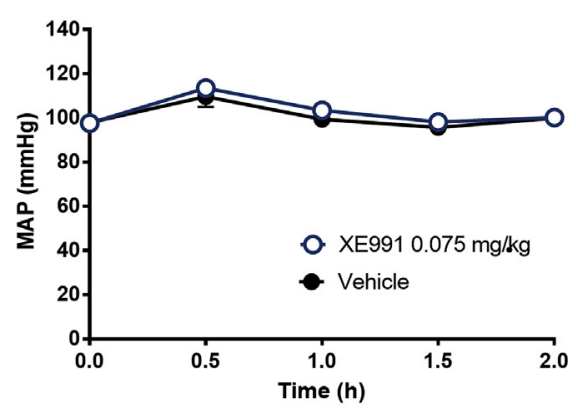

B

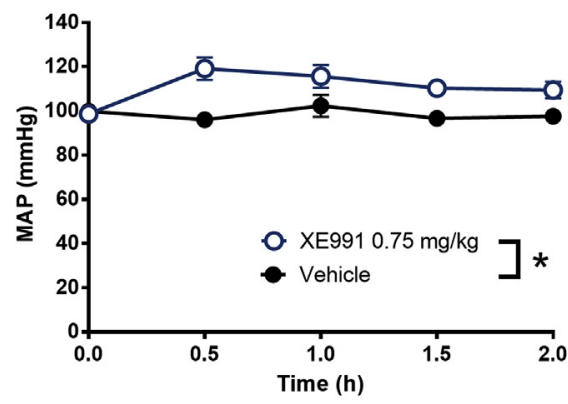

C

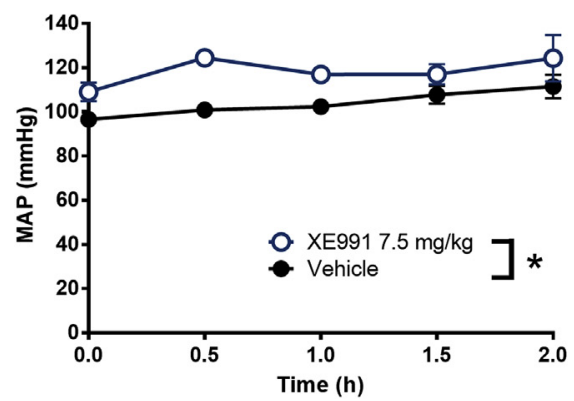

D

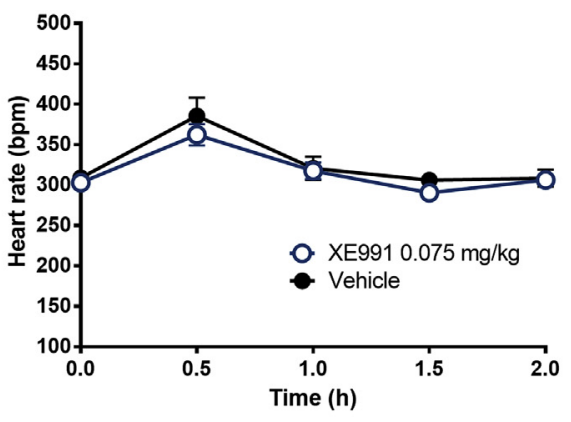

E

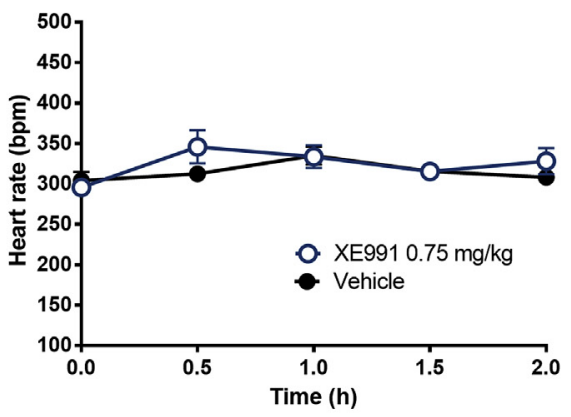

$\mathbf{F}$

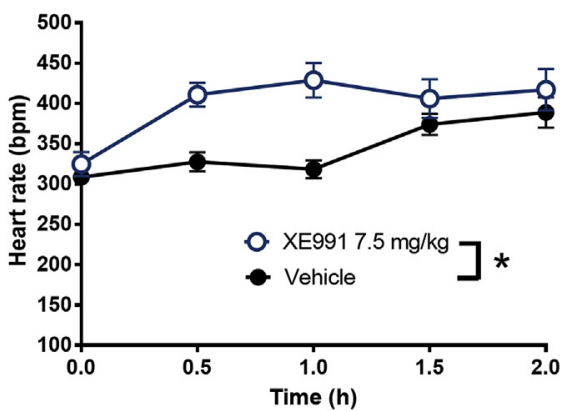

Fig. 2. Mean arterial blood pressure (MAP) and heart rate in conscious rats. MAP after administration of, respectively, (A) $0.075 \mathrm{mg} / \mathrm{kg}$, (B) $0.75 \mathrm{mg} / \mathrm{kg}$ and (C) $7.5 \mathrm{mg} / \mathrm{kg}$ of XE991. Heart rate after administration of, respectively, (D) $0.075 \mathrm{mg} / \mathrm{kg}$, (E) $0.75 \mathrm{mg} / \mathrm{kg}$ and (F) $7.5 \mathrm{mg} / \mathrm{kg}$ of XE991. MAP and heart rate are presented every $30 \mathrm{~min} \pm 4 \mathrm{~min}$, the baseline is $12 \mathrm{~min} \pm 4 \mathrm{~min}$ before each XE991 administration. $\mathrm{n}=6-9$. * $\mathrm{P}<0.05$ versus vehicle.

\subsection{Statistical analysis}

Radiotelemetry MAP and heart rate recordings were evaluated using a 2-way ANOVA, comparing baseline MAP before each XE991 administration with the MAP every following $30 \mathrm{~min}$ until $2 \mathrm{~h}$. Myograph results were evaluated by 2-way ANOVA comparing to vehicle-treated preparations. Action potentials were evaluated using a paired $t$-test comparing XE991 traces with vehicle action potentials recorded before XE991 application. Weight, age, mortality, comparison between AAR, amount of anesthesia and infarct size in animals subjected to AMI were evaluated by 1-way ANOVA, followed by Tukey's multiple comparison post hoc test when appropriate. MAP and heart rate in anesthetized animals were evaluated from the time of XE991/DMSO administration and every 30th $\mathrm{min} \pm 3 \mathrm{~min}$ until the end of the experiment by a 1-way ANOVA with repeated measures followed by Tukey's multiple comparison post hoc test. Statistical analysis of the data was performed using GraphPad Prism (Graphpad Software, La Jolla, CA, version 5.02). All data are presented as means \pm S.E.M. $\mathrm{P}<0.05$ was considered statistically significant.

\section{Results}

\subsection{Telemetric blood pressure studies and ECG measurements}

In the telemetry studies performed in conscious rats, $0.075 \mathrm{mg} / \mathrm{kg}$ XE991 did not change MAP (Fig. 2A). Administration of $0.75 \mathrm{mg} / \mathrm{kg}$ and $7.5 \mathrm{mg} / \mathrm{kg}$ XE991 increased MAP (Fig. 2B and C), while the heart rate was only significantly different from vehicle-treated animals after the administration of the highest dose of XE991 (Fig. 2D-F). Six rats were treated with vehicle, and nine rats were treated with XE991. Four out of nine rats (44\%) died $2.2 \mathrm{~h} \pm 0.4 \mathrm{~h}$ after injection of $7.5 \mathrm{mg} / \mathrm{kg}$ XE991.

Compared to vehicle, XE991 induced marked changes in the ECG (Fig. 3A-F). XE991 increased P wave amplitude and duration, increased the PR interval, prolonged the $\mathrm{QT}_{\mathrm{C}}$, and increased the $\mathrm{T}$ amplitude at 0.075 and $0.75 \mathrm{mg} / \mathrm{kg}$, while the $\mathrm{T}$ wave was reversed at the high dose of $7.5 \mathrm{mg} / \mathrm{kg}$ of XE991 (Table 1). A pronounced change induced by XE991 in the ECG was reduction in the amplitude of the QRS complex (Fig. 3 D-F, Supplementary Table 1). 
A

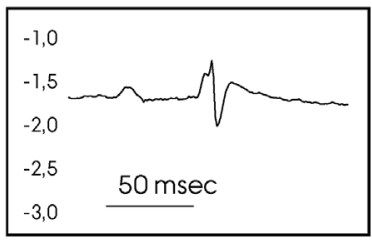

B
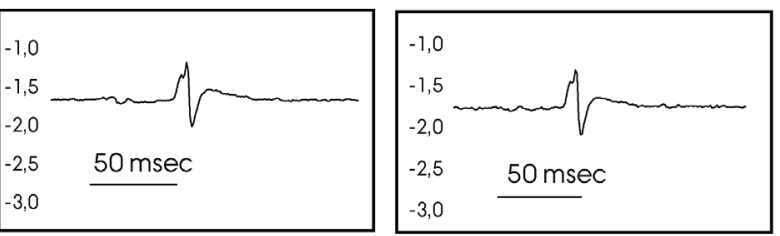

C

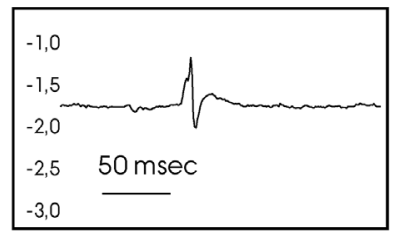

$30 \mathrm{~min}$

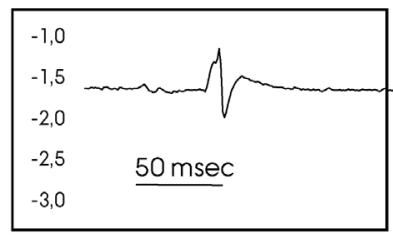

$-3,0$

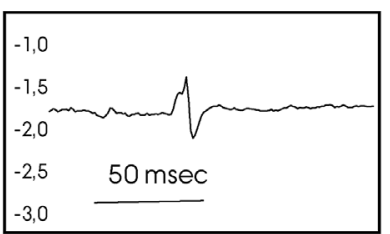

$\mathrm{D}$

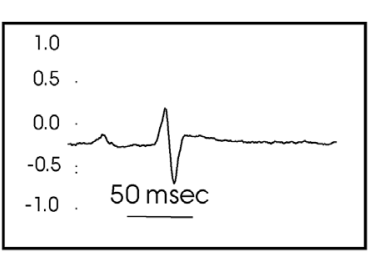

$\mathrm{E}$
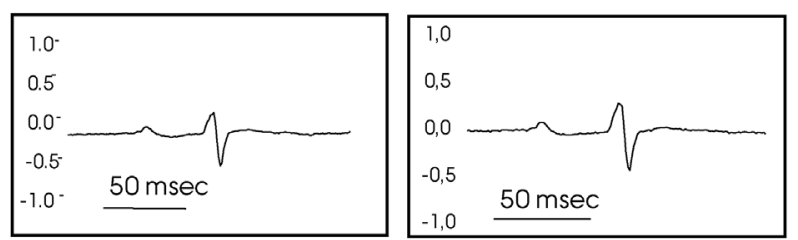

$\mathrm{F}$

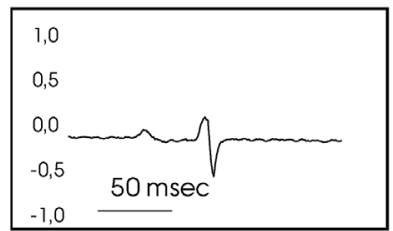

$30 \mathrm{~min}$
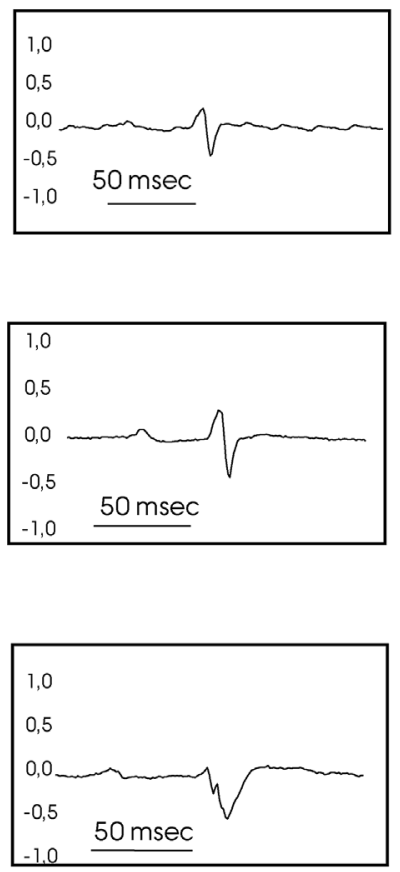

Fig. 3. Original traces showing the effect of vehicle and XE991 on electrocardiographic recordings (lead II) in the rat heart. (A-C) Effect on the ECG 2 and $30 \mathrm{~min}$ after injection of vehicle. (D-F) Effect on the ECG 2 and $30 \mathrm{~min}$ after injection of XE991 (D) $0.075 \mathrm{mg} / \mathrm{kg}$, (E) $0.75 \mathrm{mg} / \mathrm{kg}$, and (F) $7.5 \mathrm{mg} / \mathrm{kg}$. Please see Table 1 for the quantitative data.

In contrast to animals administered vehicle, $50 \%$ of the anesthetized rats injected with XE991 developed myoclonus ranging from small twitches in the lower limbs, jaw muscles and abdominal skin to shaking of the head. Generalized myoclonus was observed in two out of eight animals administered $7.5 \mathrm{mg} / \mathrm{kg}$ XE991 (see also supplementary video). In summary, these results show that XE991 increases blood pressure induced marked changes in ECG, and in high doses is associated with skeletal muscle contractions in intact animals.

Supplementary video related to this article can be found at https:// doi.org/10.1016/j.ejphar.2019.172820.

\subsection{Effect of XE991 on small rat mesenteric arteries}

Added at baseline tension, XE991 $\left(10^{-7}-10^{-4} \mathrm{M}\right)$ failed to induce contraction. In arteries contracted with phenylephrine to $20 \%$ of their maximum response, XE991 concentration-dependently increased vascular tone compared to vehicle (Fig. 4A). In arteries contracted with the thromboxane analog, U46619 $\left(10^{-7} \mathrm{M}\right)$, the $\beta$-adrenoceptor agonist isoprenaline, induced concentration-dependent relaxations that were inhibited in the presence of XE991 $\left(10^{-5} \mathrm{M}\right)$ (Fig. 4B). In summary, XE991 increases contraction and inhibits vasorelaxation in resistance arteries, and this may explain the increase in blood pressure.

\subsection{Effect of XE991 on rat cardiac action potentials}

In the intact rats, there were marked changes in the ECG. In intact atrial preparations in vitro, incubation with XE991 $\left(10^{-5} \mathrm{M}\right)$ failed to change the membrane potential (Fig. 5A), and the duration of action potential at the level of $90 \%$ repolarization was unchanged (Fig. 5B). XE991 $\left(10^{-5} \mathrm{M}\right)$ tended to slow spontaneous beating rate of right atrial preparations by $3.3 \pm 1.5 \%$, but this effect was not significant. As a control, the same experiment was conducted in hearts from guinea-pigs, and in these atrial preparations, XE991 prolonged the action potentials (Supplementary Fig. S1). The cardiac $\mathrm{I}_{\mathrm{Ks}}$ channel is a macromolecular complex composed of a pore-forming $\alpha$ (KCNQ1 or $\mathrm{K}_{\mathrm{V}} 7.1$ ) subunit and modulatory $\beta$ (KCNE1) subunit, as well as intercellular proteins (Osteen et al., 2010). Our findings suggest that there is no direct effect of XE991 on cardiomyocytes of intact rats, unlike the myocytes of species, e.g. guinea-pigs with profound cardiac $\mathrm{I}_{\mathrm{Ks}}$ current.

\subsection{Hemodynamic effects of IPC and $K_{V} 7$ channel blockade}

In the anesthetized rats, the age, weight and amount of anesthesia did not differ among the four experimental groups subjected to AMI. Several rats were excluded from the study due to development of arrhythmia or heart failure and hypotension (Table 2). MAP was significantly higher in the two experimental groups receiving XE991 compared to the vehicle (Fig. 6A). The MAP in the XE991 group was slightly but statistically lower than in the XE991 + IPC group. In all four groups, the blood pressure was reduced over time (Fig. 6A). The heart rate was significantly lower in the IPC group compared to the vehicle (Fig. 6B), but there was no statistical difference between the vehicle and any other group. In agreement with the observations in conscious animals, XE991 increases blood pressure, while IPC decreases heart rate in rats subjected to ischemia-reperfusion injury.

\subsection{Effect of IPC and $K_{V} 7$ channel blockade on infarct size}

We monitored the oxygen saturation throughout the protocol, and in all experimental groups, the mean saturation was held stable above $97 \%$ from the beginning of the protocol until the LAD occlusion, and it was considered sufficient for normal tissue function (data not shown).

The AAR was calculated based on the infusion of Evans blue, and there was no significant difference of the AAR normalized to the total weight of the heart in the four groups (data not shown). In the vehicletreated rats, the myocardial infarcts were apparent and at gross examination larger than in the rats given IPC, suggesting a cardioprotective effect of the procedure (Fig. 7A-D). Indeed, infarct size/AAR was reduced from $53 \pm 2 \%$ in the vehicle group $(n=8)$ to $36 \pm 3 \%$ in the IPC group $(n=9)$. Similarly, infarct size/AAR was significantly 


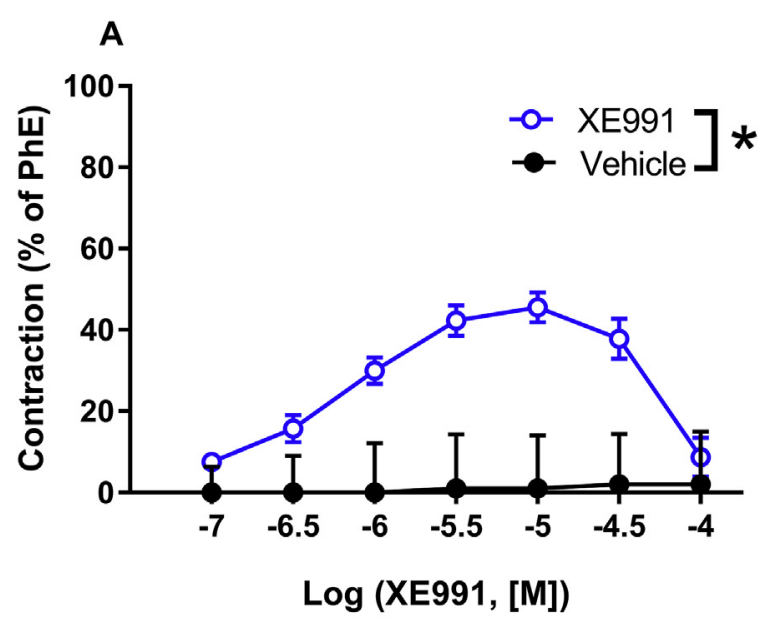

B

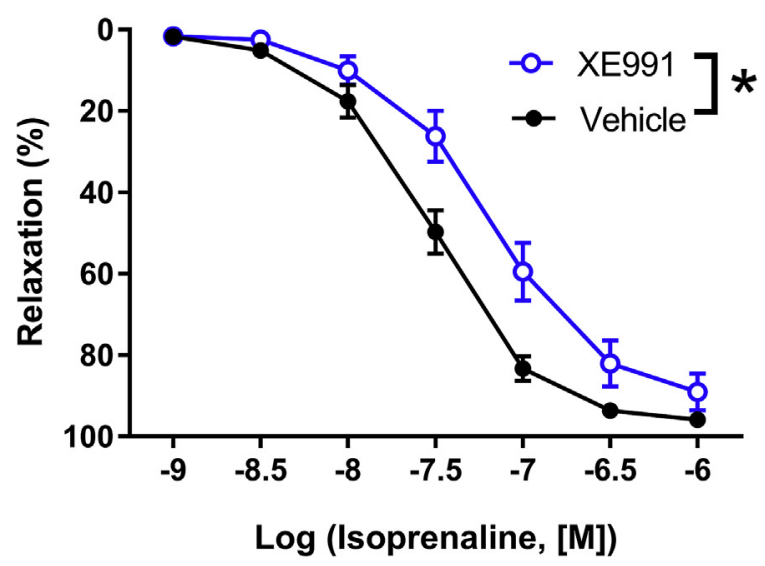

Fig. 4. Effect of XE991 in small rat mesenteric arteries on contraction and relaxation. (A) Rat mesenteric arteries contracted with phenylephrine to $20 \%$ of the maximum contraction, and cumulative concentration-response curves were constructed for of XE991 and equal amounts of the vehicle (without XE991). (B) Preparations contracted with the thromboxane analog U46619 $\left(10^{-7} \mathrm{M}\right)$. Concentration-dependent relaxations induced by isoprenaline were inhibited in the presence of $10^{-5}$ M XE991. Data are means \pm S.E.M. $\mathrm{n}=6$. $* \mathrm{P}<0.05$.

reduced to $36 \pm 3 \%$ in the group receiving both XE991 and IPC $(n=9)$, and there was no difference between the IPC and XE991 + IPC group (Fig. 7E). Treatment with only the $\mathrm{K}_{\mathrm{V}} 7$ channel blocker XE991 failed to reduce infarct size/AAR ( $48 \pm 5 \%, \mathrm{n}=9$ ) compared to the vehicle (Fig. 7E). Infarct size was plotted against MAP, and across the four experimental groups, we did not observe a direct relation of infarct size to MAP (Fig. 7F). In summary, there is effect of IPC on myocardial infarct size, while there is no effect of XE991.

\section{Discussion}

Recently, we found that IPC and the $\mathrm{K}_{\mathrm{V}} 7$ channel blocker XE991 are cardioprotective in isolated rat hearts (Hedegaard et al., 2016). To avoid pronounced increases in MAP, myoclonus, and death, we chose to administer $0.75 \mathrm{mg} / \mathrm{kg}$ XE991, which increased MAP and caused ECG changes but failed to protect the heart against ischemia-reperfusion injury. In contrast, we found that IPC also exerts cardioprotective effect in intact rats.

\subsection{Hemodynamic effects of IPC and XE991}

In conscious rats, XE991 dose-dependently increased MAP, as there 
A

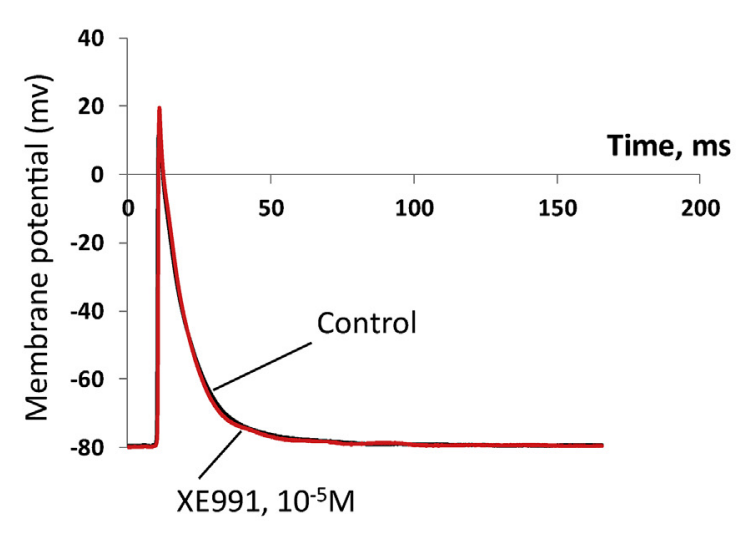

B

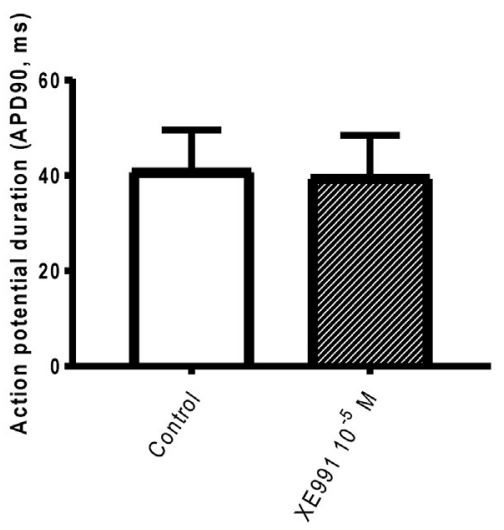

Fig. 5. Action potential in intact rat right atrium preparations. (A) Original action potential traces in one representative preparation in control conditions and after $7 \mathrm{~min}$ of perfusion with $10^{-5} \mathrm{M}$ XE991. (B) Mean action potential duration (APD) at $90 \%$ repolarization level in control and the presence of XE991. Data are means \pm S.E.M. $\mathrm{n}=5 .{ }^{*} \mathrm{P}<0.05$ versus vehicle action potentials recorded prior to XE991 application.

Table 2

Animal characteristics and exclusions in the acute myocardial infarction study.

\begin{tabular}{|c|c|c|c|c|c|c|}
\hline \multirow[t]{2}{*}{ Group } & \multirow[t]{2}{*}{ Number of animals } & \multirow[t]{2}{*}{ Body weight } & \multicolumn{2}{|l|}{ Reason for exclusion } & \multirow[t]{2}{*}{ Mortality rate } & \multirow[t]{2}{*}{ Included } \\
\hline & & & Malignant arrhythmia & Hypotension, heart failure & & \\
\hline Vehicle & 14 & $315 \pm 32 \mathrm{~g}$ & & 6 & $43 \%$ & 8 \\
\hline IPC & 17 & $321 \pm 35 \mathrm{~g}$ & 2 & 6 & $47 \%$ & 9 \\
\hline XE991 & 16 & $313 \pm 28 \mathrm{~g}$ & & 7 & $44 \%$ & 9 \\
\hline XE991 + IPC & 17 & $319 \pm 33 \mathrm{~g}$ & & 8 & $47 \%$ & 9 \\
\hline Total & 64 & & 2 & 27 & & 35 \\
\hline
\end{tabular}

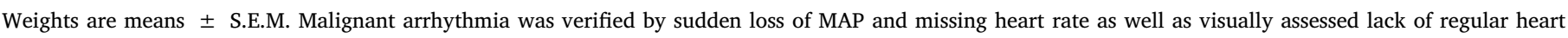
function.

A

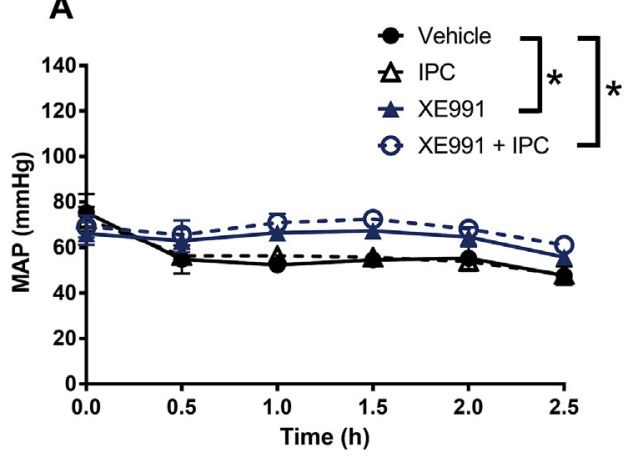

B

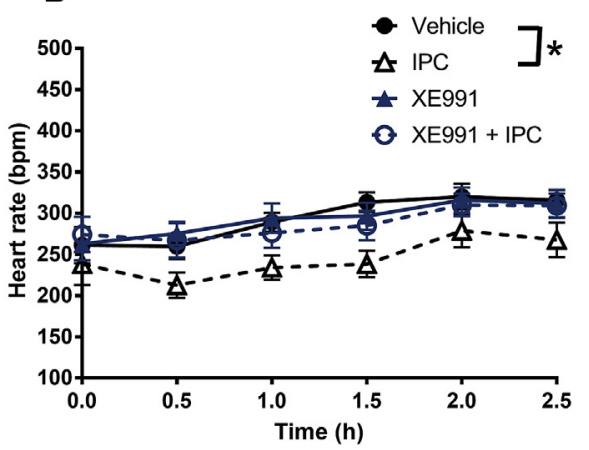

Fig. 6. Mean arterial blood pressure (MAP) and heart rate in anesthetized rats with acute myocardial infarction (AMI). (A) MAP in the four experimental groups during and after the AMI procedure. MAP is presented every $30 \mathrm{~min} \pm 3 \mathrm{~min}$ after XE991 or DMSO administration and until the end of the experiment. (B) Heart rate of the four groups during and after the AMI procedure. Heart rate is presented every $30 \mathrm{~min} \pm 3 \mathrm{~min}$ after XE991 or vehicle administration and until the end of the experiment. $* \mathrm{P}<0.05$ versus vehicle. $\mathrm{n}=7-9$. bpm, beats per min. was no response to administration of $0.075 \mathrm{mg} / \mathrm{kg}$ XE991, but marked MAP increases with higher doses of XE991 Administration of $0.75 \mathrm{mg} /$ $\mathrm{kg}$ XE991 in anesthetized rats, independent of IPC, also increased MAP. The heart rate did not differ between the vehicle and the XE991-treated groups suggesting that XE991 increases peripheral resistance. Indeed, XE991 induces vasoconstriction in murine isolated arteries and LAD (Yeung et al., 2007; Hedegaard et al., 2016; Khanamiri et al., 2013), and human mesenteric arteries ( $\mathrm{Ng}$ et al., 2011). In the present study, XE991 in isolated rat mesenteric arteries increased contractions induced by the $\alpha$-adrenoceptor agonist, phenylephrine, and inhibited relaxations induced by the $\beta$-adrenoceptor agonist, isoprenaline. These findings support vasoconstriction underlies the increase in MAP caused by XE991.

The mixture of ketamine and xylazine is known to reduce cardiac output and blood pressure compared to other anesthetics (Plante et al., 2006; Shekarforoush et al., 2016; Stein et al., 2007) because xylazine activates central $\alpha_{2}$-adrenoceptors and reduces sympathetic nerve activity and thereby blood pressure. In the present study, the baseline
MAP was also lower in the anesthetized compared to the conscious animals, and MAP decreased over time in all four experimental groups. Several animals developed heart failure due to infarcted myocardium and impaired heart function after ischemia-reperfusion (Table 2), and this is also reflected in the overall decrease in MAP. However, there was no relation of infarct size to MAP across the four experimental groups. We chose the mixture of S-ketamine and xylazine for the anesthesia to avoid the volatile anesthetics, since they exert cardioprotective effects themselves (Ludwig et al., 2003; Tsutsumi et al., 2006), and opioids protect the heart against ischemia-reperfusion injury and abolish the cardioprotective effect of IPC (Schultz et al., 1995, 1996; Gross et al., 2004). Furthermore, ketamine and xylazine reduce ventricular fibrillation compared to pentobarbital anesthesia, which may be important since malignant arrhythmias are common in the AMI rat model (Shekarforoush et al., 2016; Opitz et al., 1995). Indeed, in our study, only two rats died of malignant arrhythmia.

Some studies have found a significantly lower heart rate in the IPC group before 45-min occlusion, and at the end of the reperfusion period 
A

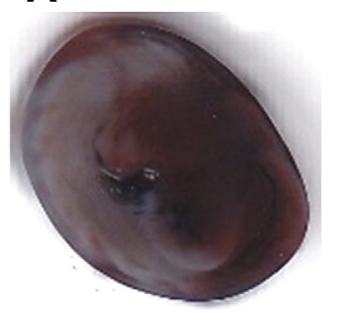

B

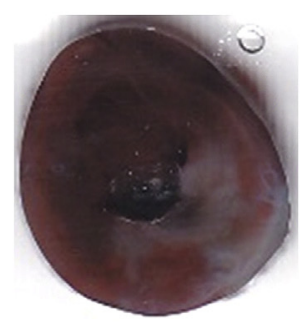

C

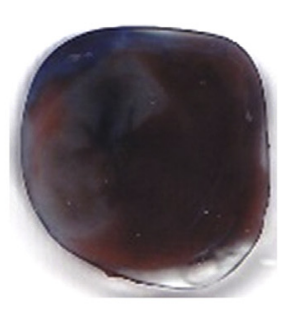

D

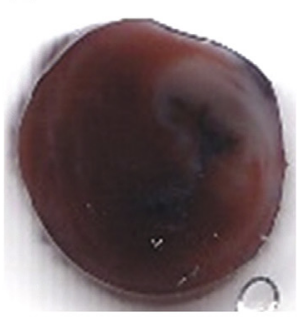

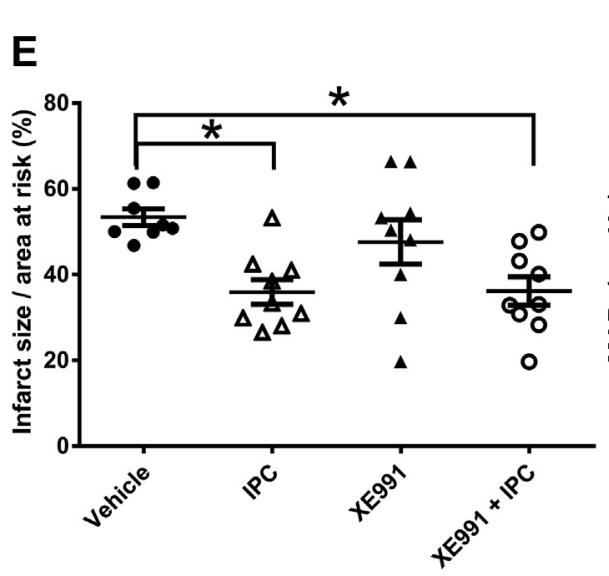

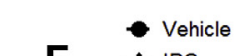

F $\triangle \mathrm{IPC}$

\pm XE991

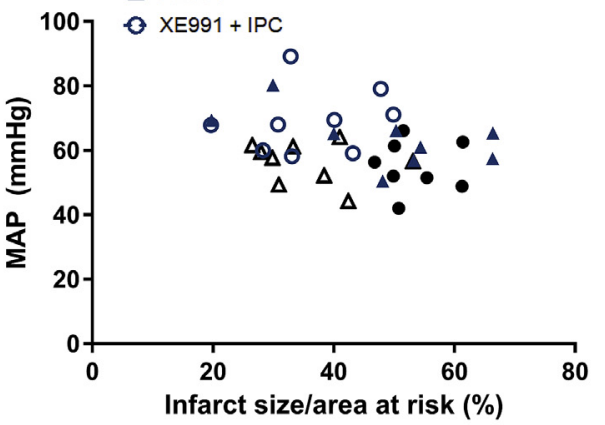

Fig. 7. Effect of ischemic preconditioning (IPC) and XE991 on myocardial infarct size. Transverse slices of hearts after staining with Evans blue and TTC (2,3,5-triphenyltetrazolium chloride), examples from the experimental groups: vehicle (A), IPC (B), XE991 (C) and XE991 + IPC (D). Pale areas were infarcted, red areas were at risk for infarction, and the dark areas were well-perfused withblood. (E) Average effect of Kv7 blockade $(0.75 \mathrm{mg} / \mathrm{kg}$ XE991) and IPC on myocardial infarct size (IS). (F) Normalized infarct size (IS/AAR) plotted against meanarterial blood pressure (MAP). There was no relation. ${ }^{*} \mathrm{P}<0.05$ versus vehicle. $\mathrm{n}=8-9$.
(Matsumura et al., 2000; Gourine et al., 2005), although this is not a consistent finding. We also observed that the IPC group had a lower heart rate than the other experimental groups. In previous studies in isolated hearts, coronary arteries, and isolated cardiomyocytes, hypoxia was found to increase $\mathrm{K}_{\mathrm{V}} 7$ channel activation, an effect blocked by XE991 (Khanamiri et al., 2013; Hedegaard et al., 2014). In the present study, the decrease in heart rate in the rats exposed to IPC was abolished in the presence of XE991. These findings suggest an involvement of $\mathrm{K}_{\mathrm{V}} 7$ channels in the reduction of heart rate in rats exposed to IPC, although further studies will be required to elucidate the significance of these findings.

\subsection{Effect of IPC and XE991 on infarct size}

IPC was reported to protect the human heart against ischemic injury and to reduce adverse cardiac events following heart surgery (Davies et al., 2013; Heusch and Rassaf, 2016). However, other studies do not find better clinical outcome for patients subjected to IPC (Walsh et al., 2016; Hausenloy et al., 2015). Although many animal models do not take into account age and disease-related changes such as atherosclerosis, diabetes, and hypertension, there is abundant evidence showing IPC induces a reduction in infarct size in ischemia-reperfusion studies in animals (Murry et al., 1986; Piot et al., 1997). In the present study, ischemia was induced for $40 \mathrm{~min}$ followed by reperfusion similar to our previous studies in isolated rat hearts (Hedegaard et al., 2016), and also used in intact animal studies by others (Lai et al., 2015; Macchi et al., 2014; Kalakech et al., 2014). The infarct size of 50\% of the AAR induced in the intact animals in the present study is similar to that reported by others (Wojciechowska et al., 2013; Uryash et al., 2012; Cheng et al., 2010). Moreover, in the present study IPC significantly reduced infarct size, supporting that it has a cardioprotective effect.

We found that blockade of $\mathrm{K}_{\mathrm{V}} 7$ channels with XE991 protected the isolated rat heart against ischemia-reperfusion injury and that combining IPC and XE991 had an additive protective effect (Hedegaard et al., 2016). In contrast, the systemic administration of XE991 failed to protect the heart against reperfusion injury in the present study, and there was no additive effect of treatment with XE991 in rats undergoing
IPC before the ischemia-reperfusion. Other studies have found cardioprotective effects of pharmacological agents in isolated, Langendorff perfused hearts, but not in clinical trials (Wang et al., 2007; Roolvink et al., 2016; Lee et al., 2017; Roos et al., 2016). In previous studies on isolated hearts, XE991 $(10 \mu \mathrm{M})$ was administered directly in circulating buffer before the occlusion and for the rest of the experiment (Hedegaard et al., 2016). In the present study, XE991 was administered systemically, allowing less control of the precise concentration of XE991 in the heart, but an estimated concentration of $1 \mu \mathrm{M} \mathrm{XE991.}$ XE991 $(0.6-0.8 \mu \mathrm{M})$ blocks the $\mathrm{K}_{\mathrm{V}} 7.1, \mathrm{~K}_{\mathrm{V}} 7.2$, and heterotetramers of $\mathrm{K}_{\mathrm{V}} 7.2$ and $\mathrm{K}_{\mathrm{V}} 7.3$ channels, while the sensitivity of $\mathrm{K}_{\mathrm{V}} 7.4$ is $3-5 \mu \mathrm{M}$ (Wang et al., 1998; Sogaard et al., 2001), and of $\mathrm{K}_{\mathrm{V}} 7.5$ 60-65 $\mu \mathrm{M}$ to XE991 (Schroeder et al., 2000). Thus, in the isolated heart studies, XE991 will block the $K_{V} 7.1-7.4$ channels while there will be much less effect on the $\mathrm{K}_{\mathrm{V}} 7.4$ channel in the present study in the intact animals. $\mathrm{K}_{\mathrm{V}} 7.4$ channels in the rat cardiac mitochondria have been suggested to contribute to cardioprotection (Testai et al., 2016), and we may speculate that selective modulation of this channel may confer cardioprotection also in intact animals. However, the present findings suggest that the highest dose of XE991, that we can administer without considerable mortality and which has direct effect on the heart and cardiovascular system, fails to protect the heart after ischemia-reperfusion in intact animals.

Large increases in afterload were found to cause larger infarcts and to worsen recovery of mechanical function after ischemia-reperfusion (Mozaffari et al., 2006). An increase in MAP leading to increased afterload may counteract the cardioprotective effects of XE991. To address this issue, we plotted infarct size against MAP in the recovery period. There was no relation of the blood pressure and infarct size in the present study, suggesting that an increase in afterload did not counteract a cardioprotective effect of XE991. This is also supported by the observation that in animals exposed to IPC and XE991, IPC still had an cardioprotective impact despite an increase in MAP.

The dominant $\mathrm{K}_{\mathrm{V}} 7$ channels in the brain are $\mathrm{K}_{\mathrm{V}} 7.2, \mathrm{~K}_{\mathrm{V}} 7.3$, and $\mathrm{K}_{\mathrm{V}} 7.5$, while $\mathrm{K}_{\mathrm{V}} 7.4$ is rarely detected (Barrese et al., 2018). The $\mathrm{K}_{\mathrm{V}} 7$ channel opener, retigabine, is an anticonvulsant (Main et al., 2000), and tremor and impaired movements have previously been observed in 
rats given the $\mathrm{K}_{\mathrm{V}} 7$ blocker XE991 orally $(0.625 \mathrm{mg} / \mathrm{kg}$ ) (Zaczek et al., 1998). We found myoclonus in $50 \%$ of the rats treated with XE991, and after administration of the high dose of XE991 $(7.5 \mathrm{mg} / \mathrm{kg}), 44 \%$ of the rats died. Our findings of lack of effect of XE991 in the intact myocardial preparations also support that the effect of XE991 has central autonomic origin, rather than a direct effect on the myocardium in intact rats. These observations prevented us from meaningful testing of higher dose of XE991 $(7.5 \mathrm{mg} / \mathrm{kg})$ on ischemia-reperfusion. Given there is no cardioprotective effects of a lower dose of XE991, other approaches including chemical modification of XE991 to avoid central effects or selective modulation of $\mathrm{K}_{\mathrm{V}} 7.4$ channels, will be required to clarify whether cardioprotection in intact animals is feasible by targeting $\mathrm{K}_{\mathrm{V}} 7$ channels.

\section{Conclusion and perspective}

The main findings of the present study are that IPC exerts cardioprotective effects in rats in vivo, and despite XE991 had cardiovascular effects reflected by increased MAP in both anesthetized and conscious animals, systemic administration of XE991 failed to protect the heart against ischemia-reperfusion injury. This contrasts with our previous studies showing that XE991 is cardioprotective in the isolated rat heart (Hedegaard et al., 2016). It would be a perspective to optimize and aim for testing drugs targeting the $\mathrm{K}_{\mathrm{V}} 7$ channel subtypes in the heart, and to avoid that it affects the $\mathrm{K}_{\mathrm{V}} 7$ channels in the brain and increases the afterload by activation of $\mathrm{K}_{\mathrm{V}} 7$ channels in the vasculature.

\section{Declaration of competing interest}

None declared.

\section{Acknowledgments and funding sources}

K. Corydon was supported by a scholarship from Aarhus University Research Foundation, U. Simonsen and E.R. Hedegaard were supported by the Danish Heart Foundation (grant 17-R116-A7616-22074). The study was also supported by Jens Anker Andersens Foundation, Helge and Peter Kornings Foundation, Direktør Kurt Bønnelycke and wife Mrs Grethe Bønnelyckes Foundation, Helge Peetz and Verner Peetz and wife Vilma Peetz grant.

\section{Appendix A. Supplementary data}

Supplementary data to this article can be found online at https:// doi.org/10.1016/j.ejphar.2019.172820.

\section{References}

Abramochkin, D.V., Hassinen, M., Vornanen, M., 2018. Transcripts of Kv7.1 and MinK channels and slow delayed rectifier $\mathrm{K}(+)$ current (IKs) are expressed in zebrafish (Danio rerio) heart. Pflüg. Arch. 470, 1753-1764. https://doi.org/10.1007/s00424018-2193-1.

Bangshaab, M., Gutierrez, A., Huynh, K.D., Knudsen, J.S., Arcanjo, D.D.R., Petersen, A.G., et al., 2019. Different mechanisms involved in liraglutide and glucagon-like peptide-1 vasodilatation in rat mesenteric small arteries. Br. J. Pharmacol. 176, 386-399. https://doi.org/10.1111/bph.14534.

Barrese, V., Stott, J.B., Greenwood, I.A., 2018. KCNQ-encoded potassium channels as therapeutic targets. Annu. Rev. Pharmacol. Toxicol. 58, 625-648. https://doi.org/10. 1146/annurev-pharmtox-010617-052912.

Bentzen, B.H., Osadchii, O., Jespersen, T., Hansen, R.S., Olesen, S.P., Grunnet, M., 2009. Activation of big conductance $\mathrm{Ca}(2+)$-activated $\mathrm{K}(+)$ channels $(\mathrm{BK})$ protects the heart against ischemia-reperfusion injury. Pflüg. Arch. 457, 979-988. https://doi. org/10.1007/s00424-008-0583-5.

Botker, H.E., Kharbanda, R., Schmidt, M.R., Bottcher, M., Kaltoft, A.K., Terkelsen, C.J., et al., 2010. Remote ischaemic conditioning before hospital admission, as a complement to angioplasty, and effect on myocardial salvage in patients with acute myocardial infarction: a randomised trial. Lancet 375, 727-734. https://doi.org/10. 1016/s0140-6736(09)62001-8.

Cheng, Y., Zhu, P., Yang, J., Liu, X., Dong, S., Wang, X., et al., 2010. Ischaemic preconditioning-regulated miR-21 protects heart against ischaemia/reperfusion injury via anti-apoptosis through its target PDCD4. Cardiovasc. Res. 87, 431-439. https:// doi.org/10.1093/cvr/cvq082.

Comerma-Steffensen, S.G., Carvacho, I., Hedegaard, E.R., Simonsen, U., 2017. Small and intermediate calcium-activated potassium channel openers improve rat endothelial and erectile function. Front. Pharmacol. 8, 660. https://doi.org/10.3389/fphar.2017. 00660.

Davies, W.R., Brown, A.J., Watson, W., Mccormick, L.M., West, N.E., Dutka, D.P., et al., 2013. Remote ischemic preconditioning improves outcome at 6 years after elective percutaneous coronary intervention: the CRISP stent trial long-term follow-up. Circ. Cardiovasc. Interv. 6, 246-251. https://doi.org/10.1161/circinterventions.112. 000184.

Fiedler, V.B., Schneider, S., Nitz, R.E., 1982. Effects of carbocromene on ventricular fibrillation during acute myocardial ischemia in anesthetized dogs. Pharmacology 25, 96-101. https://doi.org/10.1159/000137729.

Fryer, R.M., Eells, J.T., Hsu, A.K., Henry, M.M., Gross, G.J., 2000. Ischemic preconditioning in rats: role of mitochondrial K(ATP) channel in preservation of mitochondrial function. Am. J. Physiol. Heart Circ. Physiol. 278, H305-H312.

Gourine, A.V., Molosh, A.I., Poputnikov, D., Bulhak, A., Sjoquist, P.O., Pernow, J., 2005. Endothelin-1 exerts a preconditioning-like cardioprotective effect against ischaemia/ reperfusion injury via the ET(A) receptor and the mitochondrial K(ATP) channel in the rat in vivo. Br. J. Pharmacol. 144, 331-337. https://doi.org/10.1038/sj.bjp. 0706050.

Gross, E.R., Hsu, A.K., Gross, G.J., 2004. Opioid-induced cardioprotection occurs via glycogen synthase kinase beta inhibition during reperfusion in intact rat hearts. Circ. Res. 94, 960-966. https://doi.org/10.1161/01.res.0000122392.33172.09.

Hausenloy, D.J., Candilio, L., Evans, R., Ariti, C., Jenkins, D.P., Kolvekar, S., et al., 2015. Remote ischemic preconditioning and outcomes of cardiac surgery. N. Engl. J. Med. 373, 1408-1417. https://doi.org/10.1056/NEJMoa1413534.

Hedegaard, E.R., Johnsen, J., Povlsen, J.A., Jespersen, N.R., Shanmuganathan, J.A., Laursen, M.R., et al., 2016. Inhibition of KV7 channels protects the rat heart against myocardial ischemia and reperfusion injury. J. Pharmacol. Exp. Ther. 357, 94-102. https://doi.org/10.1124/jpet.115.230409.

Hedegaard, E.R., Nielsen, B.D., Kun, A., Hughes, A.D., Kroigaard, C., Mogensen, S., et al., 2014. KV 7 channels are involved in hypoxia-induced vasodilatation of porcine coronary arteries. Br. J. Pharmacol. 171, 69-82. https://doi.org/10.1111/bph. 12424.

Heusch, G., Rassaf, T., 2016. Time to give up on cardioprotection? A critical appraisal of clinical studies on ischemic pre-, post-, and remote conditioning. Circ. Res. 119 676-695. https://doi.org/10.1161/circresaha.116.308736.

Jensen, H.S., Callo, K., Jespersen, T., Jensen, B.S., Olesen, S.P., 2005. The KCNQ5 potassium channel from mouse: a broadly expressed M-current like potassium channel modulated by zinc, pH, and volume changes. Mol. Brain Res. 139, 52-62. https://doi. org/10.1016/j.molbrainres.2005.05.007.

Kalakech, H., Hibert, P., Prunier-Mirebeau, D., Tamareille, S., Letournel, F., Macchi, L., et al., 2014. RISK and SAFE signaling pathway involvement in apolipoprotein A-Iinduced cardioprotection. PLoS One 9, e107950. https://doi.org/10.1371/journal. pone. 0107950.

Khanamiri, S., Soltysinska, E., Jepps, T.A., Bentzen, B.H., Chadha, P.S., Schmitt, N., et al., 2013. Contribution of Kv7 channels to basal coronary flow and active response to ischemia. Hypertension 62, 1090-1097. https://doi.org/10.1161/hypertensionaha. 113.01244.

Lai, C.C., Tang, C.Y., Chiang, S.C., Tseng, K.W., Huang, C.H., 2015. Ischemic preconditioning activates prosurvival kinases and reduces myocardial apoptosis. J. Chin. Med. Assoc. 78, 460-468. https://doi.org/10.1016/j.jcma.2015.04.006.

Laursen, M., Beck, L., Kehler, J., Christoffersen, C.T., Bundgaard, C., Mogensen, S., et al., 2017. Novel selective PDE type 1 inhibitors cause vasodilatation and lower blood pressure in rats. Br. J. Pharmacol. 174, 2563-2575. https://doi.org/10.1111/bph. 13868.

Lee, K.H., Ha, S.J., Woo, J.S., Lee, G.J., Lee, S.R., Kim, J.W., et al., 2017. Exenatide prevents morphological and structural changes of mitochondria following ischaemiareperfusion injury. Heart Lung Circ. 26, 519-523. https://doi.org/10.1016/j.hlc. 2016.08.007.

Li, Y.W., Whittaker, P., Kloner, R.A., 1992. The transient nature of the effect of ischemic preconditioning on myocardial infarct size and ventricular arrhythmia. Am. Heart J. 123, 346-353.

Ludwig, L.M., Patel, H.H., Gross, G.J., Kersten, J.R., Pagel, P.S., Warltier, D.C., 2003. Morphine enhances pharmacological preconditioning by isoflurane: role of $\mathrm{mi}-$ tochondrial K(ATP) channels and opioid receptors. Anesthesiology 98, 705-711.

Macchi, L., Moussa, W.B., Guillou, S., Tamareille, S., Lamon, D., Prunier, D., et al., 2014. The synthetic pentasaccharide fondaparinux attenuates myocardial ischemia-reperfusion injury in rats via STAT-3. Shock 41, 166-171. https://doi.org/10.1097/ shk.0000000000000072.

Mackie, A.R., Brueggemann, L.I., Henderson, K.K., Shiels, A.J., Cribbs, L.L., Scrogin, K.E., et al., 2008. Vascular KCNQ potassium channels as novel targets for the control of mesenteric artery constriction by vasopressin, based on studies in single cells, pressurized arteries, and in vivo measurements of mesenteric vascular resistance. J. Pharmacol. Exp. Ther. 325, 475-483. https://doi.org/10.1124/jpet.107.135764.

Mackie, A.R., Byron, K.L., 2008. Cardiovascular KCNQ (Kv7) potassium channels: physiological regulators and new targets for therapeutic intervention. Mol. Pharmacol. 74, 1171-1179. https://doi.org/10.1124/mol.108.049825.

Main, M.J., Cryan, J.E., Dupere, J.R., Cox, B., Clare, J.J., Burbidge, S.A., 2000 Modulation of KCNQ2/3 potassium channels by the novel anticonvulsant retigabine. Mol. Pharmacol. 58, 253-262.

Matsumura, K., Komori, S., Takusagawa, M., Osada, M., Tanabe, F., Itoh, M., et al., 2000 Protein kinase $\mathrm{C}$ is involved in cardioprotective effects of ischemic preconditioning on infarct size and ventricular arrhythmia in rats in vivo. Mol. Cell. Biochem. 214, $39-45$. 
Mozaffari, M.S., Patel, C., Schaffer, S.W., 2006. Mechanisms underlying afterload-induced exacerbation of myocardial infarct size: role of T-type $\mathrm{Ca} 2+$ channel. Hypertension 47, 912-919. https://doi.org/10.1161/01.hyp.0000209940.65941.46.

Mulvany, M.J., Halpern, W., 1977. Contractile properties of small arterial resistance vessels in spontaneously hypertensive and normotensive rats. Circ. Res. 41, 19-26.

Murry, C.E., Jennings, R.B., Reimer, K.A., 1986. Preconditioning with ischemia: a delay of lethal cell injury in ischemic myocardium. Circulation 74, 1124-1136.

Ng, F.L., Davis, A.J., Jepps, T.A., Harhun, M.I., Yeung, S.Y., Wan, A., et al., 2011. Expression and function of the $\mathrm{K}+$ channel KCNQ genes in human arteries. Br. J. Pharmacol. 162, 42-53. https://doi.org/10.1111/j.1476-5381.2010.01027.x.

Opitz, C.F., Mitchell, G.F., Pfeffer, M.A., Pfeffer, J.M., 1995. Arrhythmias and death after coronary artery occlusion in the rat. Continuous telemetric ECG monitoring in conscious, untethered rats. Circulation 92, 253-261.

Osteen, J.D., Sampson, K.J., Kass, R.S., 2010. The cardiac IKs channel, complex indeed Proc. Natl. Acad. Sci. U. S. A. 107, 18751-18752. https://doi.org/10.1073/pnas. 1014150107.

Ovize, M., Kloner, R.A., Przyklenk, K., 1994. Stretch preconditions canine myocardium. Am. J. Physiol. 266, H137-H146. https://doi.org/10.1152/ajpheart.1994.266.1. H137.

Piot, C.A., Padmanaban, D., Ursell, P.C., Sievers, R.E., Wolfe, C.L., 1997. Ischemic preconditioning decreases apoptosis in rat hearts in vivo. Circulation 96, 1598-1604.

Plante, E., Lachance, D., Roussel, E., Drolet, M.C., Arsenault, M., Couet, J., 2006. Impact of anesthesia on echocardiographic evaluation of systolic and diastolic function in rats. J. Am. Soc. Echocardiogr. 19, 1520-1525. https://doi.org/10.1016/j.echo.2006. 06.011 .

Rakestraw, D.C., Bilski, D.A., Lam, G.N., 1994. Determination of linopirdine and its Noxide metabolites in rat plasma by liquid chromatography. J. Pharm. Biomed. Anal. 12, 1055-1061. https://doi.org/10.1016/0731-7085(94)E0040-8.

Roolvink, V., Ibanez, B., Ottervanger, J.P., Pizarro, G., Van Royen, N., Mateos, A., et al., 2016. Early intravenous beta-blockers in patients with ST-segment elevation myocardial infarction before primary percutaneous coronary intervention. J. Am. Coll. Cardiol. 67, 2705-2715. https://doi.org/10.1016/j.jacc.2016.03.522.

Roos, S.T., Timmers, L., Biesbroek, P.S., Nijveldt, R., Kamp, O., Van Rossum, A.C., et al., 2016. No benefit of additional treatment with exenatide in patients with an acute myocardial infarction. Int. J. Cardiol. 220, 809-814. https://doi.org/10.1016/j. ijcard.2016.06.283.

Rundfeldt, C., 1997. The new anticonvulsant retigabine (D-23129) acts as an opener of K + channels in neuronal cells. Eur. J. Pharmacol. 336, 243-249.

Sanguinetti, M.C., Curran, M.E., Zou, A., Shen, J., Spector, P.S., Atkinson, D.L., et al., 1996. Coassembly of K(V)LQT1 and minK (IsK) proteins to form cardiac I(Ks) potassium channel. Nature 384, 80-83. https://doi.org/10.1038/384080a0.

Schroeder, B.C., Hechenberger, M., Weinreich, F., Kubisch, C., Jentsch, T.J., 2000. KCNQ5, a novel potassium channel broadly expressed in brain, mediates M-type currents. J. Biol. Chem. 275, 24089-24095. https://doi.org/10.1074/jbc. M003245200.

Schultz, J.E., Hsu, A.K., Gross, G.J., 1996. Morphine mimics the cardioprotective effect of ischemic preconditioning via a glibenclamide-sensitive mechanism in the rat heart. Circ. Res. 78, 1100-1104.

Schultz, J.E., Rose, E., Yao, Z., Gross, G.J., 1995. Evidence for involvement of opioid receptors in ischemic preconditioning in rat hearts. Am. J. Physiol. 268, H2157-H2161.

Shekarforoush, S., Fatahi, Z., Safari, F., 2016. The effects of pentobarbital, ketaminepentobarbital and ketamine-xylazine anesthesia in a rat myocardial ischemic reperfusion injury model. Lab. Anim. 50, 179-184. https://doi.org/10.1177/ 0023677215597136.
Sogaard, R., Ljungstrom, T., Pedersen, K.A., Olesen, S.P., Jensen, B.S., 2001. KCNQ4 channels expressed in mammalian cells: functional characteristics and pharmacology. Am. J. Physiol. Cell Physiol. 280, C859-C866. https://doi.org/10.1152/ajpcell.2001. 280.4.C859.

Stein, A.B., Tiwari, S., Thomas, P., Hunt, G., Levent, C., Stoddard, M.F., et al., 2007. Effects of anesthesia on echocardiographic assessment of left ventricular structure and function in rats. Basic Res. Cardiol. 102, 28-41. https://doi.org/10.1007/ s00395-006-0627-y.

Testai, L., Barrese, V., Soldovieri, M.V., Ambrosino, P., Martelli, A., Vinciguerra, I., et al., 2016. Expression and function of Kv7.4 channels in rat cardiac mitochondria: possible targets for cardioprotection. Cardiovasc. Res. 110, 40-50. https://doi.org/10. 1093/cvr/cvv281.

Tinel, N., Lauritzen, I., Chouabe, C., Lazdunski, M., Borsotto, M., 1998. The KCNQ2 potassium channel: splice variants, functional and developmental expression. Brain localization and comparison with KCNQ3. FEBS Lett. 438, 171-176.

Tsutsumi, Y.M., Patel, H.H., Lai, N.C., Takahashi, T., Head, B.P., Roth, D.M., 2006. Isoflurane produces sustained cardiac protection after ischemia-reperfusion injury in mice. Anesthesiology 104, 495-502.

Uryash, A., Wu, H., Bassuk, J., Kurlansky, P., Adams, J.A., 2012. Preconditioning with periodic acceleration (pGz) provides second window of cardioprotection. Life Sci. 91, 178-185. https://doi.org/10.1016/j.lfs.2012.06.031.

Walsh, M., Whitlock, R., Garg, A.X., Legare, J.F., Duncan, A.E., Zimmerman, R., et al., 2016. Effects of remote ischemic preconditioning in high-risk patients undergoing cardiac surgery (Remote IMPACT): a randomized controlled trial. CMAJ (Can. Med. Assoc. J.) 188, 329-336. https://doi.org/10.1503/cmaj.150632.

Wang, H.S., Brown, B.S., Mckinnon, D., Cohen, I.S., 2000. Molecular basis for differential sensitivity of KCNQ and I(Ks) channels to the cognitive enhancer XE991. Mol. Pharmacol. 57, 1218-1223.

Wang, H.S., Pan, Z., Shi, W., Brown, B.S., Wymore, R.S., Cohen, I.S., et al., 1998. KCNQ2 and KCNQ3 potassium channel subunits: molecular correlates of the M-channel. Science 282, 1890-1893.

Wang, P., Zaragoza, C., Holman, W., 2007. Sodium-hydrogen exchange inhibition and beta-blockade additively decrease infarct size. Ann. Thorac. Surg. 83, 1121-1127. https://doi.org/10.1016/j. athoracsur.2006.10.039.

Wojciechowska, M., Watroba, M., Ciuzynska, G., Bral, M., Szukiewicz, D., 2013. Ischaemic heart preconditioning in rats with adjuvant-induced arthritis. Kardiol. Pol. 71, 839-844. https://doi.org/10.5603/kp.2013.0196.

Xia, S., Lampe, P.A., Deshmukh, M., Yang, A., Brown, B.S., Rothman, S.M., et al., 2002. Multiple channel interactions explain the protection of sympathetic neurons from apoptosis induced by nerve growth factor deprivation. J. Neurosci. 22, 114-122.

Yellon, D.M., Hausenloy, D.J., 2007. Myocardial reperfusion injury. N. Engl. J. Med. 357, 1121-1135. https://doi.org/10.1056/NEJMra071667.

Yeung, S.Y., Greenwood, I.A., 2005. Electrophysiological and functional effects of the KCNQ channel blocker XE991 on murine portal vein smooth muscle cells. Br. J. Pharmacol. 146, 585-595. https://doi.org/10.1038/sj.bjp.0706342.

Yeung, S.Y., Pucovsky, V., Moffatt, J.D., Saldanha, L., Schwake, M., Ohya, S., et al., 2007. Molecular expression and pharmacological identification of a role for $\mathrm{K}(\mathrm{v}) 7$ channels in murine vascular reactivity. Br. J. Pharmacol. 151, 758-770. https://doi.org/10. 1038/sj.bjp.0707284.

Zaczek, R., Chorvat, R.J., Saye, J.A., Pierdomenico, M.E., Maciag, C.M., Logue, A.R., et al., 1998. Two new potent neurotransmitter release enhancers, 10,10-bis(4-pyridinylmethyl)-9(10H)-anthracenone and 10,10-bis(2-fluoro-4-pyridinylmethyl)9(10H)-anthracenone: comparison to linopirdine. J. Pharmacol. Exp. Ther. 285, 724-730. 